\title{
Levantamento das orientações de ensino da habilidade da Compreensão Oral em Língua Inglesa: olhar nos documentos Oficiais de ensino
}

\author{
Clarita Gonçalves Camargo*
}

\begin{abstract}
Resumo
Este trabalho busca analisar como é orientado o ensino da compreensão oral em língua inglesa pelos principais documentos oficiais de ensino (PCNs), $(\mathrm{PCN}+),(\mathrm{BNCC})$, entre outros, para que se possa verificar quais encaminhamentos pedagógicos são dados no tratamento dessa habilidade. É importante salientar que o ensino da oralidade assume papel importante na aprendizagem e autores como Flowerdew e Miller (2005); Field (2008) e Rost (1990) orientam que esse ensino exige do ouvinte um papel ativo. Nesta pesquisa, um levantamento desses três importantes documentos de ensino foi realizado sobre os aspectos pedagógicos no direcionamento da compreensão oral. Uma das considerações observada foi que a oralidade ainda necessita de atenção, no que se refere às características do discurso, não sabendo ao certo como o professor deve encaminhar suas práticas pedagógicas. Por outro lado, a oralidade vem assumindo uma dimensão sociocultural importante nos discursos desses documentos.
\end{abstract}

Palavra-Chave: compreensão oral, língua inglesa, documentos oficiais.

Survey of the teaching listening Comprehension in English Language: look at the Official Teaching Documents

\begin{abstract}
This paper aims to analyze how the teaching of oral comprehension in English is guided by the main official teaching documents like (PCNs), $(\mathrm{PCN}+),(\mathrm{BNCC})$, among others, so that one can verify what pedagogical referrals are given in the treatment of this ability. It is important to emphasize that the teaching of orality assumes an important role in learning and authors such as Flowerdew and Miller (2005); Field (2008) and Rost (1990) point out that this teaching requires the listener to play an active role. For the data collection, the speeches of these important documents were observed and after a critical reflection on the pedagogical aspects of teaching. One of the notes observed was that orality still needs attention, regarding the characteristics of the discourse, not knowing for sure how the teacher should direct his pedagogical practices. On the other hand, orality has assumed an important social and cultural dimension in the discourses of these documents.

Keywords: listening comprehension, english language, official teaching documents.
\end{abstract}

\section{Introdução}

O presente artigo é parte de uma dissertação de mestrado que realizou um breve levantamento das orientações curriculares (PCNs), das orientações curriculares de documentos oficiais de ensino nos estados de Santa Catarina, Paraná e Rio Grande do Sul. Além disso, um outro levantamento das orientações pelo PCN+ e BNCC foi feito,

\footnotetext{
* Graduação em Letras - Português Inglês, Especialização em Literatura Brasileira e História Nacional pela UTFPR, mestrado Linguística pela UFSC e cursa doutorado em Letras pela UFPR. E-mail: clarita_camargo@yahoo.com.br.
} 
no intuito de verificar mais profundamente como vem sendo interpretado o ensino da compreensão oral (CO). A escolha por esses documentos justifica-se por oferecer um panorama de orientações direcionadas ao ensino no sul do país. O objetivo deste estudo é compreender de que maneira é dado o encaminhamento pedagógico em compreensão oral, para que professores e pesquisadores da área da linguística aplicada possam refletir sobre essas orientações de forma mais crítica. O ensino da compreensão oral em língua inglesa é visto como complexo e ainda pouco ensinado na educação básica devido à suposta ênfase na habilidade da leitura.

Entende-se que a compreensão oral envolve uma série de conhecimentos desde os conhecimentos linguísticos, pragmáticos e cognitivos que atuam durante a mensagem e fazem dela um processo ativo e de grande demanda (ROST, 1990). É importante lembrar que a proposta deste estudo é refletir sobre os discursos que pairam sobre a aprendizagem e verificar se eles corroboram com as perspectivas teóricas a esse ensino.

\section{Abordagens Pedagógicas no ensino da compreensão oral}

No método áudio-lingual, na década de 60, a compreensão oral era promovida a partir da exposição do aluno à repetição de frases, sentenças e textos com vistas ao desenvolvimento da competência linguística do aprendiz. A partir da década de 70, com a noção de competência comunicativa (HYMES, 1972), a compreensão oral passou a ser pensada em contexto de uso da LE/L2. Na década de 80, com a Hipótese do Insumo Compreensível (KRAHEN, 1982), a compreensão da linguagem escrita e oral constituiu construto teórico fundamental para o entendimento do processo de aquisição de uma LE/L2. No entanto, a relação entre compreensão e aquisição recebeu críticas na literatura. Sharwood Smith (1986), por exemplo, defendeu que a compreensão e a aquisição são processos distintos e, por essa razão, a aquisição de um item linguístico da LE/L2 pode acontecer com ou sem a sua compreensão. Na visão deste e de outros autores, é possível adquirir uma estrutura sem necessariamente compreendê-la, como aquelas que compõem expressões formulaicas (McLAUGHLIN, 1987, p. 40). Essas expressões são fragmentos de fala, submetidas ou não à análise, que podem ser utilizadas em situações de uso comunicativo. Para McLaughlin (1987), o acesso ao insumo compreensível não constitui, portanto, o único caminho para a aquisição. Ellis (2001) também criticou a relação entre compreensão e aquisição, questionando o nível 
necessário de compreensão em contexto de uso comunicativo da LE para que a aquisição possa realmente acontecer.

$\mathrm{Na}$ década de 80 , buscou-se criar situações comunicativas em sala de aula que pudessem levar à prática da oralidade em atividades pré-comunicativas e comunicativas (LITTLEWOOD, 1981). O objetivo dessas atividades era fazer com que os aprendizes pudessem associar formas linguísticas às suas funções comunicativas e aos seus significados funcionais, relacionando, assim, a linguagem aos seus significados sociais (LITTLEWOOD, 1981). Como Littlewood (1981, p. 12) explica:

\begin{abstract}
Um passo inicial nesta direção é tirar a atividade da dependência do professor ou da fita cassete, de modo que os alunos comecem a interagir como parceiros iguais em uma troca conversacional, ao invés de meramente reagir a estímulos. Por exemplo, após um período inicial, quando os alunos aprendem a dar e a rejeitar sugestões sob o controle do professor [...], eles podem ser solicitados a interagir em pares. Um aluno pode receber um conjunto de pistas que indique as sugestões que ele deve fazer, enquanto o colega responde, seja de acordo com a sua preferência pessoal, seja a partir de um segundo conjunto de pistas visuais (LITTEWOOD, 1981, p. 12, tradução minha).
\end{abstract}

Através de atividades desse tipo, a aprendizagem de LE/L2, segundo o autor, é promovida em contexto de interação social, que acontece quando o aprendiz necessita da informação do colega, criando assim lacunas de informação entre os usuários da L2/LE e um propósito para a comunicação entre eles. Deste modo, a língua pode expressar significado funcional e social. Em atividades comunicativas, "o desempenho dos aprendizes torna-se menos controlado por estímulos linguísticos específicos e mais controlado pela necessidade de se produzir linguagem, em resposta às exigências funcionais e sociais em interações sociais" (LITTLEWOOD, 1981 p. 15). Assim, o uso de atividades pré-comunicativas e comunicativas, propostas por Littlewood (1981), para desenvolverem a produção e compreensão oral, visava ao desenvolvimento linguístico através do desempenho comunicativo.

Ainda na década de 80 , a habilidade de compreensão oral foi também desenvolvida a partir de tarefas comunicativas. O termo tarefa foi conceituado, na época, como

[...] uma atividade ou ação que é realizada como o resultado do processamento ou entendimento da língua (i.e. como resposta). Por exemplo, desenhar um mapa enquanto se ouve uma fita ouvir uma instrução 
para realizar um comando podem ser denominadas tarefas. As tarefas podem ou não envolver a produção da língua. Uma tarefa geralmente requer que o professor especifique o que será considerado como uma resposta bem sucedida15 (RICHARDS et al., 1986, p. 289, tradução minha).

Outras definições de tarefa também foram propostas nessa década, como a de Prabhu (1987) e a de Nunan (1989). Prabhu (1987) também recorreu à noção de tarefa para o seu projeto de ensino de inglês na Índia, com o objetivo de desenvolver a competência linguística dos aprendizes nessa língua por meio da compreensão de insumo escrito e oral em uso comunicativo da língua. Independentemente dessas noções, as atividades de compreensão oral, na década de 80 , passaram a considerar a natureza comunicativa da linguagem. Para Richards e Rodgers, (1986, p. 71), as características de um ensino comunicativo seguem os seguintes pressupostos:

1. A língua é um sistema para a expressão de significados. 2. A função básica da linguagem é a interação e comunicação. 3. A estrutura da língua reflete seus usos funcionais e comunicativos. 4. As unidades básicas da língua não são meramente seus traços gramaticais e estruturais, mas as categorias de significado funcional e comunicativo em um discurso (RICHARDS; RODGERS, 1986, p. 71).

Além dessas características, é consenso na literatura que o ensino comunicativo tem como objetivo desenvolver a competência comunicativa do aprendiz na L2/LE (BROWN, 1994; LI, 1998; MAIA et al., 2002). De acordo com Brown (1994), o desenvolvimento da competência comunicativa deve ser promovido a partir de um contexto de comunicação, em que os aprendizes têm que lidar com os mais variados tipos de sub competências, como a competência linguística que exige certo domínio da língua, a sociolinguística a qual o indivíduo deverá conhecer as marcas da oralidade de certos grupos sociais, a discursiva em reconhecer a intencionalidade do falante e seus propósitos comunicativos e a pragmática como, por exemplo, testar hipóteses e fazer inferências. Nas palavras de Almeida Filho (1998, p. 36),

o ensino comunicativo é aquele que organiza as experiências de aprender em termos de atividades relevantes/tarefas de real interesse e/ou necessidade do aluno para que ele se capacite a realizar a língua-alvo para realizar ações de verdade na interação com outros falantes-usuários dessa língua. 
Entende-se, com base no autor, que em qualquer proposta de ensino comunicativo de LE, as atividades de aprendizagem devem estabelecer um propósito comunicativo, um resultado a ser alcançado e uma situação real de uso da LE, o que nos remete novamente à noção de tarefa. Em conceitos mais atuais de tarefa (SKEHAN, 1998; ELLIS, 2003; XAVIER, 2011), seus elementos definidores são: foco no significado, propósito e resultado comunicativo. O desafio do professor é fazer com que o aluno reconheça que as práticas de linguagem desenvolvidas nessa língua agregam valor à sua vida. E, em se tratando da habilidade de compreensão oral, esses elementos (foco no significado, propósito e resultado comunicativo) assumem papel importante na atividade e na vida dos estudantes.

Desde a década de 90 até os dias atuais, a compreensão oral tem sido proposta de forma integrada com outras habilidades, por meio de tarefas e de outras atividades comunicativas. Entretanto, a realidade de ensino e as propostas de desenvolvimento dessa habilidade variam de contexto para contexto. Field (2008) salienta que o professor precisa conhecer as características do seu contexto de ensino, pois "se almejamos preparar o aprendiz adequadamente para situações da vida real, que envolvam a compreensão oral, precisamos avaliar até que ponto a tarefa demanda o tipo de processamento que ocorre nas extensões de sala de aula" (FIELD, 2008, p. 62). Todavia, isso não é uma questão simples de ser avaliada, pois as condições de realização da linguagem dentro e fora da escola são diferentes. Como aponta Field (2008, p. 63):

\footnotetext{
Esta linha de argumentação não se apoia em nenhum critério restrito de 'autenticidade'. Não é uma tentativa de reproduzir rigidamente as circunstâncias da vida real em um contexto inevitavelmente artificial de sala de aula. Ela simplesmente reconhece a necessidade de se fornecer treinamento [ao aluno] em tipos específicos de processos que são exigidos quando ouvimos no mundo real e que não são ativados em formatos de pergunta e resposta.
}

A autenticidade a que Field se refere está relacionada à atividade e não ao texto oral necessariamente. A atividade de compreensão oral deve envolver processos que se assemelham àqueles utilizados na vida real, como por exemplo, fazer inferências, lidar com ambiguidades, reconhecer informação redundante, entre outras (FIELD, 2008, p. 117). Essa visão difere de abordagens que priorizam a compreensão via pergunta e 
resposta (comprehension approach), sutilmente criticada pelo autor, as quais não visam a desenvolver as sub-habilidades ou os processos da compreensão oral. Em outras palavras, a maioria dos formatos das atividades de compreensão oral ainda segue modelos de questionários (pergunta e resposta) que não validam tipos específicos de processos importantes para a compreensão eficaz de um texto oral, segundo Field (2008).

A escolha do texto oral para uma atividade de compreensão é uma decisão do professor, que pode se basear nas necessidades e interesses dos alunos. Novamente, isso nos remete à familiarização do professor com o seu contexto de ensino. Algumas diretrizes curriculares para o ensino de LE recomendam o uso de gêneros de textos que circulam o universo dos alunos. Assim, a linguagem pode ser representada genuinamente, podendo as diversas características do texto oral serem percebidas, como as hesitações, os começos falsos, as pausas preenchidas, frases fragmentadas, marcadores discursivos de início e final das falas, deixes (referência fora do texto) etc.

\section{Orientações sobre o ensino da compreensão oral pelos documentos oficiais}

Os Parâmetros Curriculares Nacionais (PCNs) de Língua Estrangeira salientam a importância da habilidade de leitura, justificada pelo seu caráter social. O documento salienta que "considerar o desenvolvimento de habilidades orais [produção e compreensão oral] como central no ensino de Língua Estrangeira no Brasil não leva em conta o critério de relevância social para a sua aprendizagem” (BRASIL, 1998, p. 20). Por outro lado, o documento esclarece que "[O] foco em leitura não exclui a possibilidade de haver espaços no programa para possibilitar a exposição do aluno à compreensão e memorização de letras de música, de certas frases feitas [...]" (Ibid., p. 22).

A compreensão oral é assim vista, nesse importante documento, como habilidade secundária, vinculada "à função de aumentar a consciência linguística do aluno" (Ibid., p. 22) e a um "processo de construção de significados” (Ibid., p. 95). Para a compreensão desses significados, vários tipos de conhecimentos são necessários: o conhecimento de mundo, o sistêmico e o de organização textual, o qual se refere aos padrões de interação social, como menciona o documento em questão. O processo da compreensão escrita e oral envolve fatores relativos ao processamento da informação, 
cognitivos e sociais. Os fatores relativos ao processamento da informação têm a ver com a atenção, a percepção e decodificação dos sons e letras, a segmentação morfológica e sintática, a atribuição do significado ao nível léxico-semântico, e a integração de uma informação e outra. Os fatores cognitivos envolvem a contribuição do leitor/ouvinte, a construção do significado (a formulação de hipóteses sobre os significados possíveis com base no seu pré-conhecimento de mundo) e de organização textual e os fatores sociais, que englobam a interação/falante e escritor/ouvinte localizada na história, na instituição e na cultura. Isso significa dizer que compreender envolve crucialmente a percepção da relação interacional entre quem fala, o que, para quem, por que, quando e onde. (BRASIL, 1998, p. 89).

Não muito diferente dos PCNs de LE, as propostas curriculares de alguns estados e municípios brasileiros também consideram a compreensão oral uma habilidade não prioritária, porém ela deve estar presente na prática pedagógica por meio de textos de gêneros diversos e direcionados para o contexto real dos alunos. Nas orientações curriculares do Rio Grande do Sul (RIO GRANDE DO SUL, 2009), por exemplo, os gêneros do discurso orientam a organização do currículo de LE e são escolhidos a partir de temáticas "relevantes às diferentes etapas da vida escolar" (Ibid., p. 138). A sua escolha está atrelada a um eixo temático:

[...] levantamos diferentes sugestões de textos orais e escritos autênticos encontrados em situações sociais relacionadas às temáticas (por exemplo, para o tema Quem disse que não posso participar?, sugerimos gêneros como reportagem, legislação, debate público, relato de experiência, cartas de denúncia ou de reclamação de direitos, para citar alguns), [...] (RIO GRANDE DO SUL, 2009, p. 138).

Nesta proposta, gêneros orais como canção, notícia radiofônica, peça de teatro, trailers e resenha oral são considerados no planejamento de unidades didáticas, e devem estar articulados com as demais habilidades linguísticas (leitura, produção escrita e oral) dentro do eixo temático no qual o gênero está inserido. Com relação à compreensão oral, especificamente, percebe-se que os objetivos de ensino-aprendizagem se referem ao conhecimento interpretativo do texto oral, próximo aos sugeridos para as práticas de leitura. $\mathrm{O}$ tratamento pedagógico dado aos gêneros orais também é similar àquele proposto para os textos escritos, assim como as competências e as habilidades a serem 
desenvolvidas, como mostra o Quadro 1 a seguir, retirado do documento em questão (RIO GRANDE DO SUL, 2009, p. 152), do eixo temático "Identidades".

Quadro 1. Modelo de planejamento de unidade didática com base em gêneros do discurso, conforme as orientações curriculares do Rio Grande do Sul (2009).

\begin{tabular}{|c|c|c|}
\hline $\begin{array}{l}\text { Projetos } \\
\text { Tarefas } \\
\text { preparatórias } \\
\text { Objetivos de } \\
\text { ensino }\end{array}$ & Conteúdos relacionados & Competências/habilidades \\
\hline$[\ldots]$ & $\begin{array}{l}\text { a) Ao tema e gênero } \\
\text { (Espanhol e Inglês) } \\
\text { - canção: circulação social e } \\
\text { funções: modos de } \\
\text { organização, componentes e } \\
\text { natureza estética do texto. } \\
\text { b) Aos textos que compõe } \\
\text { [sic] as tarefas centrais e } \\
\text { preparatórias } \\
\text { Inglês } \\
\text { - notas biográficas sobre um } \\
\text { cantor: circulação social e } \\
\text { funções; modos de } \\
\text { organização, componentes e } \\
\text { natureza }\end{array}$ & $\begin{array}{l}\text { Espanhol e Inglês } \\
\text { - ativar e usar conhecimentos prévios (conhecimento } \\
\text { de mundo, experiência anterior com canções, } \\
\text { conhecimento da língua portuguesa e das línguas } \\
\text { adicionais) para ouvir, ler e produzir um texto. } \\
\text { - estabelecer relação e fazer inferências a partir da } \\
\text { integração de texto verbal e não verbal (imagens em } \\
\text { clipe, fotos, capa de }\end{array}$ \\
\hline
\end{tabular}

O que se observa nessa proposta é a falta de especificidade na forma como a compreensão oral deve ser desenvolvida na LE, pois essa habilidade envolve fatores específicos, como a fala não planejada, sua velocidade, contrações fonológicas e assimilações, ocorrências frequentes de marcadores de início e final de discurso, entre outras características que se diferenciam da leitura. Rost (1990) salientou a diferença entre o processamento de um texto oral e o de um texto escrito. Para o autor, o texto escrito oferece ao leitor maior controle sobre o insumo que está sendo compreendido em relação ao texto oral.

A abordagem de ensino mais comum para a compreensão oral tem sido a mesma que a utilizada para a leitura, segundo Flowerdew e Miller (2005), ou seja, através de perguntas de interpretação textual, como se ambas as habilidades envolvessem o mesmo processamento da linguagem. Na visão desses autores, a compreensão oral deve ir além da decodificação da informação, pois a linguagem falada "tem o potencial para muitas sutilezas emocionais, sensibilidades contextuais, influência pessoal, armadilhas interativas e referências ao mundo real, fora dos meandros do texto." (FLOWERDEW; 
MILLER, 2005, p. 51-52). Os autores concluem que há uma diferença entre textos escritose orais e, consequentemente, necessitam ser ensinados de forma diferente.

O que se depreende das orientações curriculares do Rio Grande do Sul é sua perspectiva pedagógica voltada para a consciência da noção de gênero como prática social sem, entretanto, uma proposta de desenvolvimento das (sub)habilidades linguísticas. Como Flowerdew e Miller (2005) explicam, diferentes gêneros falados e escritos podem ser situados ao longo de um contínuo de diferentes graus de spokennesse writtenness, respectivamente, exibindo uma quantidade maior ou menor de traços linguísticos distintivos de cada modalidade.

Essas diferenças pressupõem atividades e objetivos de aprendizado específicos no interior dessas modalidades. Textos orais monológicos, por exemplo, podem eventualmente compartilhar algumas similaridades com determinados textos escritos, porém conservam traços linguísticos peculiares. Os textos monológicos também se diferenciam de textos orais dialógicos, os quais também carregam elementos distintivos próprios, como a troca de turnos, regras de interrupção, entre outros elementos.

Assim como as orientações curriculares do Rio Grande do Sul e os PCNS de Língua Estrangeira, a Proposta Curricular do Estado de Santa Catarina para o ensino de LE também dá prioridade ao ensino das habilidades de leitura e escrita, devido "[a]o número de alunos por turma e a carga horária da disciplina LE" (SANTA CATARINA, 1998, p. 101), sugerindo a dificuldade de o professor trabalhar a compreensão e produção oral diante dos entraves mencionados. No entanto, é possível observar que o documento faz alusão indireta à compreensão oral quando aborda a importância do texto ${ }^{1}$ na interação entre os sujeitos: "Texto, nesta perspectiva, é unidade discursiva em uso, é recorte de um discurso falado ou escrito que tem inserção num espaço sócio cultural, de onde se tira parte de seu sentido." (Ibid., ênfase minha, p. 102). O documento propõe que o professor trabalhe com elementos característicos do texto como: "seu sentido na dimensão discursiva, a percepção de suas condições de produção, de sua orientação argumentativa, de seu(s) interlocutor(es) - enfim, de sua manifestação discursiva correspondente a um complexo e longo processo de formulação subjetiva." (Ibid., p. 102).

\footnotetext{
${ }^{1}$ Para Fávero; Koch (2009) todo texto representa uma unidade de sentido através de signos que podem ser apresentados de forma falada ou escrita. Isso envolve coesão, coerência, informatividade, intertextualidade, entre outros.
} 
Nesta mesma perspectiva, as Diretrizes Curriculares de Língua Estrangeira Moderna do Estado do Paraná também fundamentam uma proposta de ensino com base em gêneros textuais, sugerindo ao professor que aborde "os vários gêneros textuais, em atividades diversificadas, analisando a função do gênero estudado, sua composição, a distribuição de informações, o grau de informação presente ali, a intertextualidade, os recursos coesivos, a coerência e, somente depois de tudo isso, a gramática em si." (Ibid., p. 63). Percebe-se, novamente, que o encaminhamento metodológico para o texto escrito é o mesmo para o texto oral. A distinção se apresenta quando o documento mostra a importância de o aluno se familiarizar com os sons específicos da língua que está aprendendo (Ibid., p. 66).

De acordo com esse documento, "práticas de oralidade, escrita e leitura não são segmentadas, pois elas não se separam em situações concretas de comunicação" (Ibid., p. 30). Além disso, "na interação com o texto pode haver uma complexa mistura da linguagem escrita, visual e oral" (Ibid., p. 5). Nesta linha de raciocínio, a compreensão oral é tratada na interação com outras habilidades e não como uma habilidade que deva ser desenvolvida separadamente. No entanto, o documento não encaminha formas de como realizar essa integração. Embora a proposta seja interessante, as habilidades se mantêm separadas nos conteúdos básicos propostos.

Ainda nas Diretrizes Curriculares de Língua Estrangeira do Estado do Paraná, a compreensão oral acompanha a produção oral como sinalizado no uso do termo oralidade nos conteúdos estruturalizantes. Independentemente do gênero oral, seja ele "debate", "diálogo/ discussão argumentativa", "palestra", "músicas" ou "entrevista" (Ibid., p. 85), busca-se trabalhar "elementos extralinguísticos: entonação, pausas, gestos, [...]; adequação do discurso ao gênero; turnos de fala; variações linguísticas; marcas linguísticas: coesão, coerência, gírias, repetição; pronúncia" (Ibid., p. 77).

Da mesma forma que no documento oficial do estado do Rio Grande do Sul, a proposta de Língua Estrangeira do Estado do Paraná é centrada no gênero per si, em seus aspectos identitários e nas estruturas discursivas e linguísticas que o compõem, partindo de uma perspectiva de estudo do gênero ao invés de, por exemplo, partir do uso propositado e situado do texto oral por meio de tarefas.

Com essa breve análise das propostas curriculares dos três estados do sul do país, é possível observar a presença marginal do texto oral e da sua forma de tratamento 
pedagógico, geralmente equiparado ao texto escrito. Por outro lado, o que se depreende desses documentos pode favorecer a elaboração de atividades de compreensão oral a partir de considerações sobre o uso da língua(gem) como prática social, o discurso situado num determinado momento (história) e espaço (contextos culturais e institucionais) (BRASIL, 1998, p. 95) e a relação ou relevância do texto oral para realidade do aluno. Embora essas propostas curriculares salientem a grande importância da leitura crítica e da escrita para o ensino de LE, o desenvolvimento da compreensão oral ainda precisaria de maior destaque, já que a LE deve ser pensada em um contexto de uso comunicativo.

Além disso, observa-se ainda, nos dias atuais, a necessidade de o professor de LE aprofundar-se no entendimento de práticas de compreensão oral, dada a sua falta de clareza sobre como a proficiência nessa habilidade se constrói.

Passando a analisar o PCN+ verifica-se pouca especificidade no ensino da habilidade, inclusive observa-se um tratamento ancorado em competências, como por exemplo: "compreender que intenções comunicativas presidem a escolha de diferentes registros, o uso de gírias, da norma culta ou de variações dialetais.” (Ibid., p.99). Observa-se orientações em trabalhar aspectos globais, culturais, identitários que implicam na conversação. Nota-se também que é importante "selecionar vocabulário adequado para uso oral e escrito, a partir de um repertório que se amplia gradualmente ao longo dos três anos de curso." (Ibid., p. 107). O tratamento do texto escrito e oral é visto de forma a atender as características que compõe cada gênero discursivo, mas não há menção sobre a variação de aspectos fonéticos e fonológicos da língua que de certa forma deveria abranger as habilidades orais.

Para finalizar, a proposta da BNCC está pautada em habilidades a serem desenvolvidas no eixo da oralidade, leitura, escrita, conhecimentos linguísticos, gramaticais e cultural. A oralidade continua a assumir um papel secundário se comparado a leitura e aos conhecimentos linguísticos. Vejamos algumas orientações no ensino da língua inglesa:

O eixo oralidade envolve as práticas de linguagem em situações de uso oral da língua inglesa, com foco na compreensão (ou escuta) e na produção oral (ou fala), articuladas pela negociação na construção de significados partilhados pelos interlocutores e/ou participantes envolvidos, com ou sem contato face a face. Assim, as práticas de linguagem oral presenciais, com contato face a face - tais como 
debates, entrevistas, conversas/diálogos, entre outras -, constituem gêneros orais nas quais as características dos textos, dos falantes envolvidos e seus "modos particulares de falar a língua", que, por vezes, marcam suas identidades, devem ser considerados. Itens lexicais e estruturas linguísticas utilizados, pronúncia, entonação e ritmo empregados, por exemplo, acrescidos de estratégias de compreensão (compreensão global, específica e detalhada), de acomodação (resolução de conflitos) e de negociação (solicitação de esclarecimentos e confirmações, uso de paráfrases e exemplificação) constituem aspectos relevantes na configuração e na exploração dessas práticas (BRASIL, 2017, p. 243).

Em suma, observa-se que alguns gêneros orais são contemplados pelos documentos e que o trato com a oralidade assume uma perspectiva de língua global que envolve um conhecimento entre os falantes de diversas nacionalidades, ou seja, a língua é percebida como hibrida e multifacetada, já que "a língua inglesa não é mais aquela do “estrangeiro", oriundo de países hegemônicos [...] e ainda "são acolhidos e legitimados os usos que dela fazem falantes espalhados no mundo inteiro [...]” (BRASIL, 2017, p. 241). Sendo assim, parece que a oralidade vem assumindo novas perspectivas como a de língua franca. ${ }^{2}$

\section{Conclusão}

Ao levantarmos as orientações curriculares observou-se que a compreensão oral não é tratada considerando sua natureza, ou seja, como trabalhar os aspectos cognitivos importantes para o desenvolvimento do aluno. O discurso oral carrega marcas que envolvem diversas identidades linguísticas difíceis de serem trabalhadas num contexto em que pouco se conhece da cultura do outro. $\mathrm{O}$ ensino por competência parece distante num cenário em que ainda predomina um conhecimento básico da língua. A falta de especificidade de orientar o professor a trabalhar com aspectos da fonética e fonologia denota fragilidade de uma habilidade tão complexa. Por último, o texto oral parece desafiador num contexto onde ainda que se prevalece a escrita.

\section{Referências}

ALMEIDA FILHO, J. C. P. Dimensões comunicativas no ensino de língua. Campinas, SP: Pontes, 1998.

\footnotetext{
${ }^{2}$ Jenkins (2012) propõe orientações de como deve ser o ensino do inglês como língua franca e uma das propostas é saber negociar o significado de acordo com o contexto do falante. O termo língua franca, para a autora, envolve uma variedade linguística de diversas nacionalidade que usam o inglês para se comunicar.
} 
BRASIL. Base Nacional Comum Curricular. 2. Versão. Abril, 2017. Disponível em: http://basenacionalcomum.mec.gov.br/documentos/bncc-2versao.revista.pdf Acesso em: 15 ago. 2017.

BRASIL. Ministério da Educação. PCN Ensino Médio Orientações Educacionais Complementares aos Parâmetros Curriculares Nacionais. Linguagens códigos e suas tecnologias. Brasília: Secretaria da Educação, 1998. Disponível em: http://www.mec.gov.br. Acesso em: 20 set. 2018.

BRASIL. PCN+ ensino médio: orientações educacionais complementares aos Parâmetros Curriculares Nacionais. Ciências da natureza, matemática e suas tecnologias. Brasília: 2002.

BROWN, H. D. Teaching by principles: an interactive approach to language pedagogy. Englewood Cliffs: Prentice Hall Regents, 1994.

ELLIS, R. Non-reciprocal task, comprehension and second language acquisition. In: BYGATE, M. P.; SKEHAN, P.; SWAIN, M. (Eds.) Researching pedagogical tasks: Second language learning, teaching and testing, Essex: Pearson Education Limited, 2001, p. 49-74.

FAVERO, L. L.; KOCH, I. G. V. Linguística Textual: uma introdução. 3 ed. São Paulo; Cortez, 2009.

FIELD, J. Listening in the language classroom. Cambridge: Cambridge University Press, 2008.

FLOWERDEW, J. Academic listening. Cambridge: CUP, 1994.

FLOWERDEW, J; MILLER, L. Second language listening: theory and practice, Cambridge: CUP, 2005.

GOVERNO DO ESTADO DO PARANÁ. Diretrizes Curriculares de Língua Estrangeira Moderna para a Educação Básica no Paraná. Curitiba: Secretaria da Educação, 2002.

HYMES, D. On communicative competence. In: PRIDE, J. B; HOLMES, J. (Orgs.) Sociolinguistics: Selected Readings. Harmondsworth: Penguin, p. 269-293, 1972.

JENKINS, J. English as a Lingua Franca from the classroom to the classroom.LT Journal Volume 66/4 Special issue October 2012.

LITTLEWOOD, W. Communicative language teaching: an introduction. Cambridge: Cambridge University Press, 1981.

MCLAUGHLIN, B. Theories of second language acquisition. London: Edward Arnold, 1987. 
PARANÁ. Secretaria de Estado da Educação - Departamento de Ensino Fundamental. Diretrizes Curriculares Estaduais - Língua Estrangeira Moderna (versão preliminar). Curitiba: SEED/PR, 2005.

PRABHU, N. S. Procedural syllabuses. In: READ, J. A. S. (Ed.). Trends in language syllabus design. Cingapura: SUP, p. 272 - 280, 1984.

KRASHEN, S. Principles and practice in second language acquisition. Oxford: Pergamon Press, 1982.

RICHARDS, J. C; RODGERS. T. S. Approaches and methods in language teaching: a description and analysis. Cambridge: Cambridge University Press, 1986.

RIO GRANDE DO SUL. Secretaria de Estado da Educação. Departamento Pedagógico (Org.) Referências curriculares do estado do Rio Grande do Sul: linguagens, códigos e suas tecnologias. Porto Alegre: SE/DP, 2009. 258p. Disponível em: http://educacao.rs.gov/dados/refer_currc_vol1pdf. Acesso em: 20 set. 2018.

ROST, M. Listening in language learning. New York: Longman, 1990.

SANTA CATARINA, Secretaria de Estado da Educação e do Desporto. Proposta curricular de Santa Catarina. Florianópolis: COGEN, 1998. 